\title{
陕北子洲黄土丘陵区古聚淡洪水沉积层的确定及其 产沙模数的研究
}

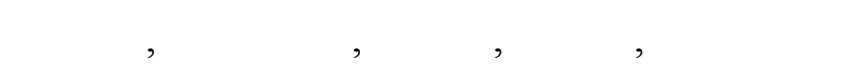

(1) 中国科学院、水利部成都山地灾害与环境研究所, 成都 610041 ;

(2) 中国科学院研究生院, 北京 100049 ;

(3) 中国科学院、水利部水土保持研究所黄土高原土壤侵蚀与旱地农业实验室, 杨凌 712100 ;

(4) 黄河上中游管理局, 西安 710075;

(5) 黄河水利科学研究院, 郑州 450003

E-mail: wingoflong@gmail.com

2008-03-26 收稿, 2008-09-03 接受

国家自然科学基金(批准号: 90502002, 40671120)和黄土高原土壤侵蚀与旱地农业国家重点实验室开放基金(编号: 10501-156)资助项目

Long Y, Zhang X B, Li M, et al. Identification of the deposited layers in landslides reservoir and investigation of the sediment yields during the later sixteenth century on the Hill Loess Plateau, China. Chinese Science Bulletin, 2008, 53(24): 3908-3913

doi: 10.1007/s11434-008-0466-3

摘要 陕北黄土丘陵区聚湫坝和淤地坝众多, 以子洲县黄土洼古聚湫为研究对象, 采集了总深度 达 $12.73 \mathrm{~m}$ 的沉积泥沙剖面样品. 根据泥沙粒度和狍粉浓度的变化, 将全剖面分为 54 个洪水沉积 层. 并根据剖面中融冻扰动层的分布, 将 54 个洪水沉积层分为 31 个年度的洪水沉积层的组合. 根据雉台法计算, 每次暴雨洪水的产沙模数介于 715.53 30376.47 $\mathrm{t} \cdot \mathrm{km}^{-2}$, 平均 $7105.87 \mathrm{t} \cdot \mathrm{km}^{-2}$; 年产沙模数介于 968.36 55579.37 $\mathrm{t} \cdot\left(\mathrm{km}^{2} \cdot \mathrm{a}\right)^{-1}$, 平均 $12629.49 \mathrm{t} \cdot\left(\mathrm{km}^{2} \cdot \mathrm{a}\right)^{-1}$, 与淮宁河中游年输沙 量相近, 表明该地区明代的土壤侵蚀强度与现代接近. 31 个年度的后 5 年产沙模数急剧增加, 5 年 内的年均产沙模数达 $31309.12 \mathrm{t} \cdot\left(\mathrm{km}^{2} \cdot \mathrm{a}\right)^{-1}$, 结合明代当地戍边屯厓的历史分析, 这一现象应为滑 坡灾害发生后新的土地大开发所造成.

关键词

黄土丘陵区

小流域

坝库淤积

产沙量
20 世纪初以来，采用水文站、径流小区仪器观测， 测定大、小河流的输沙量和坡面的土壤侵蚀量, 可 靠、准确地给出了黄土高原各地的现代土壤侵蚀强 度. 查明历史时期的土壤侵蚀强度对正确认识黄土 高原水土流失的发展过程及其原因有重要的意义. 已有的研究主要通过历史文献记载的环境变迁分析 历史时期的水土流失状况，或根据黄河下游冲积扇 不同历史时期的沉积量反演黄土高原的水土流失状 况, 难以定量确定历史时期的土壤侵蚀量或流域产 沙量.

20 世纪 60 年代以来, 黄土高原修建了众多的淤 地坝, 拦蓄了大量的泥沙, 这些淤地坝可视为小流域 的“沉沙池”. 张信宝等人 ${ }^{[1]}$ 在晋西离石羊道沟、陕北
子长赵家沟和安塞云台山沟等小流域，利用泥沙粒 度数据和 ${ }^{137} \mathrm{Cs}$ 等示踪技术, 区分出坝库沉积剖面的 洪水沉积旋迴, 并根据旋迴的厚度和相应的库面面 积求算了每个洪水旋迴的沉积泥沙量. 黄土高原地 区历史时期滑坡堵塞沟谷形成的古聚湫坝沉积较多, 一些聚湫形成的时间在县志等历史文献资料中有可 靠记载, 如明代隆庆三年(公元 1569 年)形成的陕北 子洲裴家湾镇黄土洼古聚湫. 古聚湫坝是典型的“间 葫芦”坝, 流域产沙全部沉积于坝库内, 如能采用恰 当技术区分聚湫坝沉积剖面的次暴雨洪水沉积层和 对沉积层进行年际划分, 就可以求算该流域当时的 次暴雨洪水产沙量和年产沙量. 2006 年, 我们在黄土 洼古滑坡堵塞的后小滩支沟, 采集了古聚湫坝沉积 
的连续剖面泥沙样品, 根据泥沙粒度和狍粉浓度变 化，进行了次暴雨洪水沉积层的划分; 根据融冻扰动 层的分布, 将 54 个洪水沉积层划分为 31 个年度的洪 水沉积组合; 最后计算了次暴雨洪水产沙模数和年 产沙模数. 本文是该研究的初步报导, 有关土地利用 /植被变化对产沙量影响的研究结果, 另文报道.

\section{1 研究区概况}

黄土洼古聚湫位于无定河支流淮宁河中游右岸 的沟掌流域内，东经 $109^{\circ} 54^{\prime}$ ，北纬 $37^{\circ} 20^{\prime}$, 行政上属 子洲县裴家湾镇黄土洼村, 北距子洲县城 $50 \mathrm{~km}$, 东 距绥德县城 $22.5 \mathrm{~km}$ (图 1). 形成该聚湫的古滑坡发生 时间在历史文献中有明确记载, 据清顺治十八年(公 元 1661 年)刻本《清涧县志》记载, “隆庆已已，黄土 坬二山崩裂成湫” (隆庆已已为明隆庆三年, 公元 1569 年). 据黄河中上游管理局实测, 沟掌流域集水 面积 $2.72 \mathrm{~km}^{2}$, 聚湫坝控制面积 $2.58 \mathrm{~km}^{2}$, 聚湫坝高 $61.22 \mathrm{~m}$,坝内淤地面积 $0.44 \mathrm{~km}^{2}$. 聚湫坝顶与坝地最 低处相对高差 $5.6 \mathrm{~m}$. 坝库面积大, 坝地渗水能力强, 进入坝库的暴雨洪水全部拦蓄于坝内, 就地入渗. 据 当地老百姓介绍, 200 余年前聚湫坝库已淤平水干,
开始耕种，具体时间不详. 古滑坡土体不仅堵塞主沟 沟道，而且也堵塞了对岸的 3 条小支沟. 这 3 条支沟 滑坡堵沟形成的坝库淤满后，洪水漫顶，坝体切开， 已切至原沟底.

研究区属典型的黄土丘陵区，沟壑深切，地貌上 可分为面积大致相等的沟间地、沟谷地 2 个单元. 沟 间地地面坡度多小于 $25^{\circ}$, 沟谷地谷坡坡度多大于 $30^{\circ}$. 沟间地几乎全为坡耕地, 侵蚀方式主要为面蚀 和细沟侵蚀; 沟谷地谷坡多为裸坡, 部分坡度小于 $40^{\circ}$ 的较缓谷坡为草坡, 植被稀疏, 侵蚀方式主要为 冲沟侵蚀和泻溜、滑坡、崩塌等重力侵蚀. 沟间地为 马兰黄土 $\left(\mathrm{Q}_{3}\right)$ 覆盖, 老黄土 $\left(\mathrm{Q}_{1-2}\right)$ 和上新世红秥土 $\left(\mathrm{N}_{2}\right)$ 从上到下出露于沟谷谷坡和支沟沟底, 聚湫坝以下 的沟掌沟下游沟床切入中生代砂岩. 黄土洼聚湫坝 上游的流域，原先深窄的沟谷被泥沙填淤为宽浅的 川地, 部分坝地的边部和梁峁坡地逐渐过渡, 浑为一 体, 难以区分. 黄土洼聚湫坝库上游和周边其他流域 相比, 沟间地侵蚀强度无差异, 但沟谷地侵蚀强度差 异很大，前者轻微，后者十分强烈.

黄土洼古滑坡堵塞主沟的同时，也将对岸的 3 条

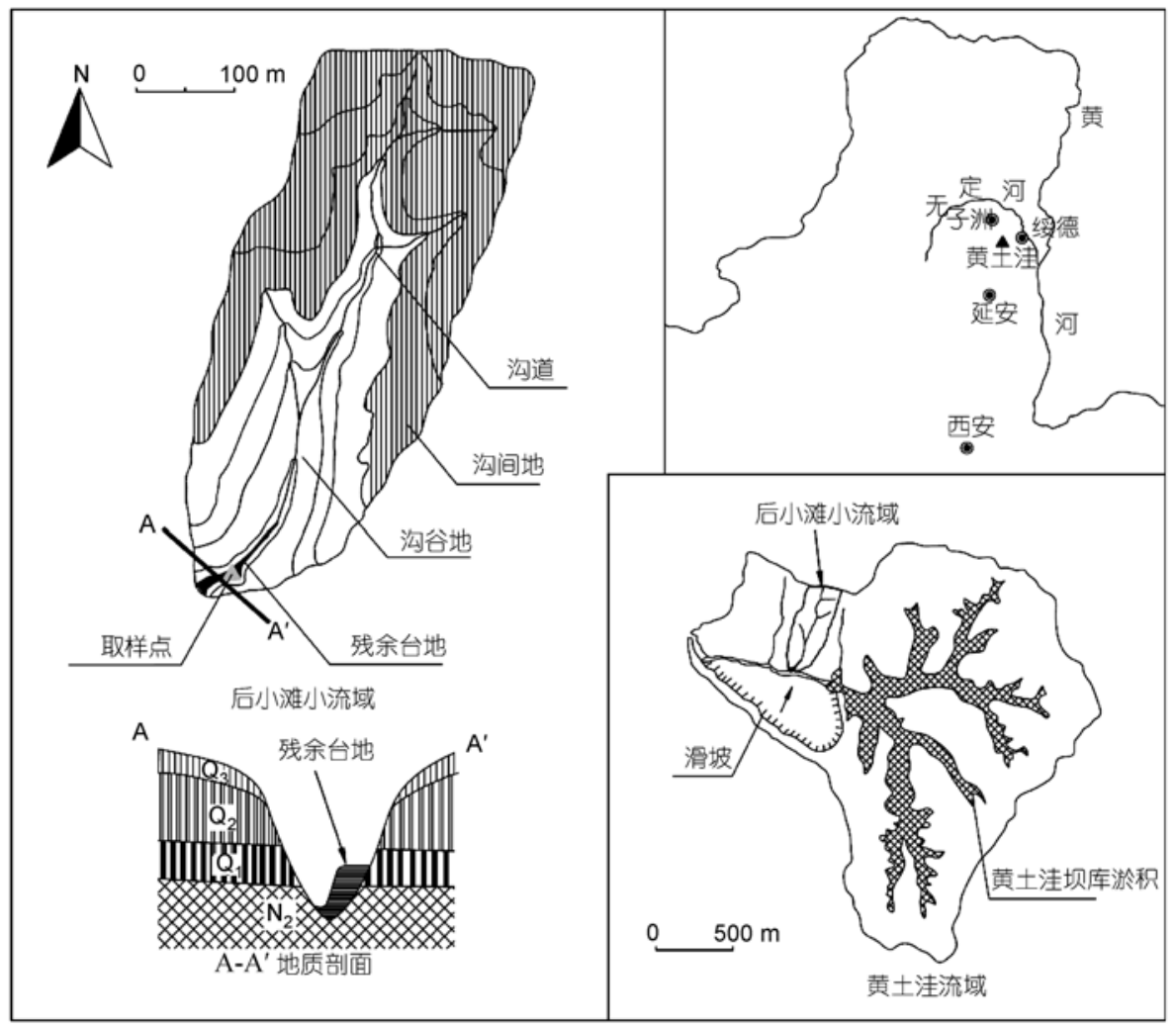

图 1 研究小流域位置示意图 
小支沟堵塞, 我们研究的后小滩沟小流域是这 3 条小 支沟中间的一条，集水面积 $0.1 \mathrm{~km}^{2}$, 为南北向的一条 狭长支沟. 沟口高程 $1030 \mathrm{~m}$, 沟头高程 $1190 \mathrm{~m}$, 相对 高差 $160 \mathrm{~m}$. 沟长 $650 \mathrm{~m}$, 沟道平均纵坡降 $24.6 \%$, 中 下部沟道较缓, $5 \%$ 左右, 沟头部分的沟道很陡, 大于 $70 \%$. 实地量测, 滑坡堵沟形成的淤积台地长 $126 \mathrm{~m}$, 沟口处台地面高出沟床 $15 \mathrm{~m}$ 左右, 残留台面最大宽 度 $24 \mathrm{~m}$. 台地下切前的台面最大宽度 $49 \mathrm{~m}$, 台地面 积 $3175 \mathrm{~m}^{2}$. 根据台地底部取样层位的追索, 该层顺 沟淤积长度 $85 \mathrm{~m}$, 沟口处宽度 $33 \mathrm{~m}$, 面积 $1407 \mathrm{~m}^{2}$. 锥台法求得坝库淤积泥沙总体积 $29533 \mathrm{~m}^{3}$. 流域内 沟间地和沟谷地面积约各占一半, 沟间地现全部为 耕地, 未退耕. 而沟谷深窄, 已切入上新世红秥土 $\left(\mathrm{N}_{2}\right)$, 沟道最宽处不到 $2 \mathrm{~m}$, 谷坡多为陡立裸坡, 切沟 侵蚀和泻溜、滑坡、崩塌等重力侵蚀强烈. 但流域中 下游台地上方的谷坡多较稳定, 坡面发黑, 部分坡度 较缓的谷坡荒草植被较好. 淤积台地面上的数亩耕 地是流域内最好的农田.

研究区气候属暖温带半干旱大陆性季风气候, 四季分明, 降水偏少, 冬季干旱寒冷. 黄土洼气候和 绥德更接近, 绥德县年均温 $9.7^{\circ} \mathrm{C}, 1$ 月均温 $-7.6^{\circ} \mathrm{C}, 7$ 月均温 $24.2^{\circ} \mathrm{C}$, 无霜期 $165 \mathrm{~d}$; 多年平均降水量 486 $\mathrm{mm}, 7 \sim 9$ 月的夏季降水占全年降水量的 $65 \%$. 陕北延 绥一带明代实行戍边屯圼制度, 土地被强度开发, 以 致“西渡黄河, 历永宁入延绥, 即山之悬崖峭壁, 无 尺寸不耕”[2]. 明代的气候相当寒冷, 为中国 5000 年 历史时期第 4 次寒冷期 ${ }^{[3]}$. 根据临近的内蒙土默川地 区历史文献资料的研究，1541 1610 年为湿期, 气候 相对湿润 ${ }^{[4]}$.

\section{2 样品采集和测试}

\section{1 沉积泥沙样品采集}

2006 年 4 月, 我们在距沟口 $30 \mathrm{~m}$ 台地的沟道侧 壁采集了坝库沉积连续剖面泥沙样品, 剖面垂直长 度 $13.23 \mathrm{~m}$, 为避免现代耕作的影响, 近地表厚 $50 \mathrm{~cm}$ 的土层未取样, 实际取样剖面的垂直长度 $12.73 \mathrm{~m}$. 最底部取样层位以下, 分布不均匀的少量沟槽沉积 (厚度 $0 \sim 1 \mathrm{~m}$ 不等)未取样. 坝库沉积直接覆盖在原 沟底的红黏土 $\left(\mathrm{N}_{2}\right)$ 上, 最底部取样层应是滑坡堵沟的 当年或次年沉积. 按沉积旋迴分层取样, 每个旋迴底 部的泥沙粗, 顶部泥沙细, 野外易于区分. 旋迴厚度 差异很大, 数厘米至数十厘米不等. 每一旋迴 3 个样
品, 顶部细颗粒层一个样品, 厚度 $0.2 \sim 2.5 \mathrm{~cm}$ 不等, 中下部沙层等厚度分为 2 个样品, 共采集了 163 个分 层泥沙样品.

\section{2 样品测试}

样品进行了粒度和狍粉分析. 粒度分析采用吸 管法测定. 孢粉分析在中国地质科学院进行, 样品前 处理采用氢氟酸法, 在每个样品中加入一定数量的 外加花粉石松(Lycopodium) 孢子. 经酸、碱处理后, 再用比重为 2.12 的重液浮选两次.

\section{3 结果与讨论}

\section{1 次洪水沉积层的确定}

剖面泥沙的细颗粒含量 $(<0.005 \mathrm{~mm})$ 和狍粉浓度 的深度变化见图 2. 每个旋迴底部的泥沙粗, 顶部的 泥沙细. 这是由于洪水进入坝库后, 泥沙在水体中逐 渐沉降, 粗泥沙沉降快, 细泥沙沉降慢. 旋迴顶部细 颗粒层的细颗粒含量 $63.6 \% \sim 8.38 \%$, 为中下部沙层的 $1 \sim 6$ 倍. 不同旋迴泥沙的平均粒度无甚差异 $(0.025$ $0.036 \mathrm{~mm})$, 但顶部层细颗粒含量有所差异, 这可能 和不同产沙洪水的洪水过程及其泥沙沉降过程不尽 相同有关. 每个旋迴底部的孢粉浓度低, 顶部的孢粉 浓度高. 这是由于孢粉粒度多介于 10 200 $\mu \mathrm{m}$ 之间, 和细粒泥沙的粒度相当, 但比重仅 $1.81 \sim 1.96$ $\mathrm{g} \cdot \mathrm{cm}^{-3[5]}$, 小于泥沙比重 $2.6 \sim 2.7 \mathrm{~g} \cdot \mathrm{cm}^{-3}$, 孢粉在水 体中的沉降较同粒径的泥沙颗粒慢, 因此富集于每 个旋迴的上部层位. 各旋迴顶部细颗粒层的狍粉浓 度远高于中下部沙层, 一般为后者的 2 20 倍; 细颗 粒层的狍粉量占旋迴狍粉总量的 $12.96 \% \sim 71.03 \%$. 不 同旋迴的孢粉平均浓度差别很大，低者 113.51 粒 $/ \mathrm{g}$, 高者 5540.77 粒 $/ \mathrm{g}$, 这主要是由于不同旋迴的源地土 壤相对产沙量不同和不同源地土壤的狍粉含量差别 又很大的缘故. 剖面孢粉浓度和细粒泥沙含量的深 度变化, 验证了野外取样的分层结果, 垂高 $12.73 \mathrm{~m}$ 的坝库沉积剖面共分为 54 个洪水沉积旋迴. 旋迴最 厚 $84 \mathrm{~cm}$, 最薄 $2.6 \mathrm{~cm}$.

\section{2 年末次洪水沉积层的确定}

野外取样时, 我们注意到旋迴顶部的细颗粒层 有两种结构, 一种为致密结构, 另一种则类似于多孔 的“冻豆腐”结构. 致密结构为正常的泥沙水下沉积 结构, “冻豆腐”结构显然不是正常的泥沙水下沉积结 构, 我们认为这是典型的被融冻过程扰动的沉积结 构. 陕北冬季干旱, 现代小流域的淤地坝多干枯. 450 


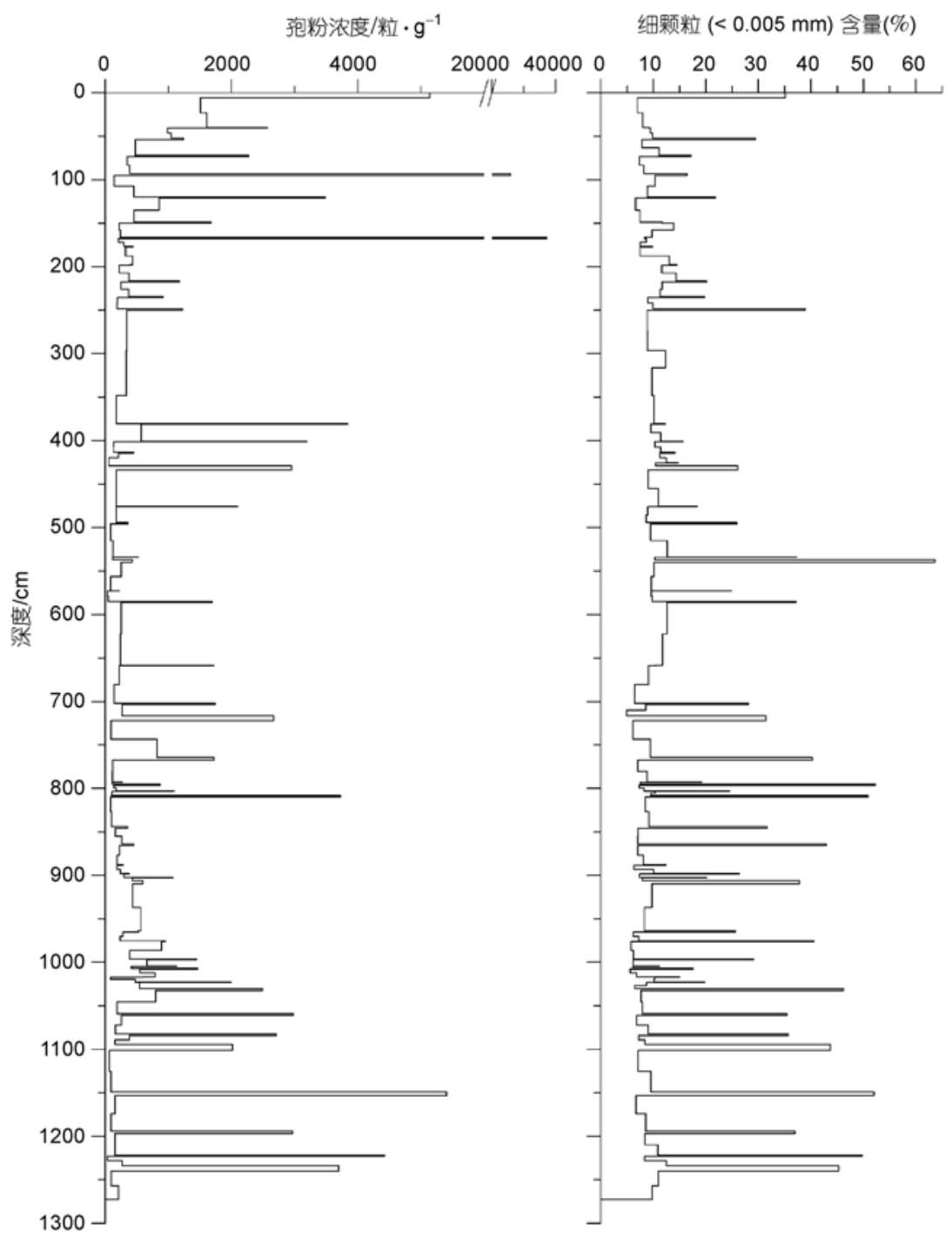

图 2 各旋迴狍粉浓度及 $<0.005 \mathrm{~mm}$ 颗粒含量随深度的变化

年前的后小滩小流域，集水面积仅 $0.1 \mathrm{~km}^{2}$, 聚湫坝 库冬季也要干枯, 每年末次洪水沉积层的顶部暴露 地面. 子洲冬季寒冷, 为季节性冻土分布区, 细颗粒 层孔隙度高, 毛细孔隙比例高, 易富水, 含水量大, 冻结后融化后形成多孔的“冻豆腐”融冻层结构. 中 下部的粉、细沙层, 孔隙度低, 含水量低, 毛细孔隙 比例低，易沥水，融冻过程不会扰动原有的沉积结构 (图 3). 我们根据融冻扰动层的分布, 进行了洪水沉 积旋迴的年际区分, 54 个洪水沉积旋迴中，共发现了 31 个年末次洪水沉积层, 也就是说 31 年发生了 54 次产沙洪水, 平均每年 1.7 次. 当然, 这 31 年不包括 未发生洪水的年份. 根据邻近的子洲岔巴沟(流域面 积 $187 \mathrm{~km}^{2}$ )的观测资料, 和子长赵家沟、安塞云台山

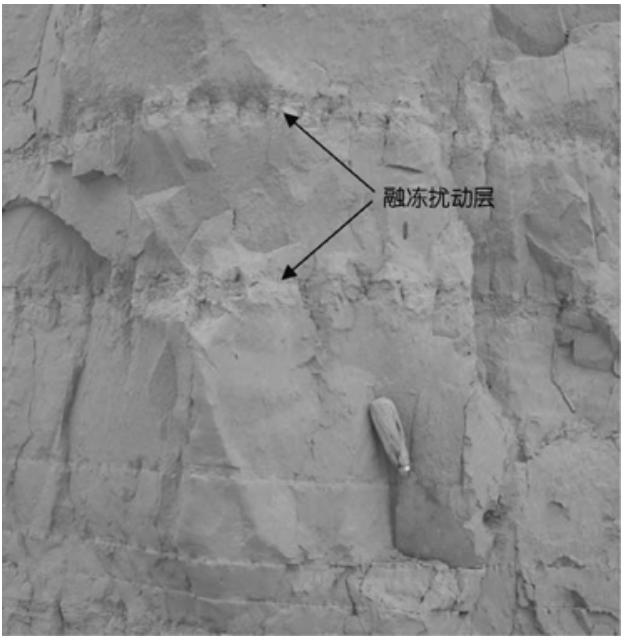

图 3 融冻扰动层结构照片 
表 1 子洲黄土洼后小滩聚淡坝库 1569 年后 54 次暴雨洪水和相应 31 年的产沙模数

\begin{tabular}{|c|c|c|c|c|}
\hline 旋迴 & 时间/a & 旋迴淤沙体积 $/ \mathrm{m}^{3}$ & 次产沙模数 $/ \mathrm{t} \cdot \mathrm{km}^{-2}$ & 年产沙模数 $/ \mathrm{t} \cdot\left(\mathrm{km}^{2} \cdot \mathrm{a}\right)^{-1}$ \\
\hline 54 & 31 & 1225.76 & 17160.70 & 30636.00 \\
\hline 53 & & 362.82 & 5079.53 & \\
\hline 52 & & 599.71 & 8395.87 & \\
\hline 51 & 30 & 622.99 & 8721.92 & 19591.89 \\
\hline 50 & & 776.43 & 10869.97 & \\
\hline 49 & 29 & 851.64 & 11922.92 & 18749.04 \\
\hline 48 & & 487.58 & 6826.12 & \\
\hline 47 & 28 & 297.19 & 4160.68 & 31989.29 \\
\hline 46 & & 589.38 & 8251.35 & \\
\hline 45 & & 522.01 & 7308.10 & \\
\hline 44 & & 494.84 & 6927.69 & \\
\hline 43 & & 381.53 & 5341.47 & \\
\hline 42 & 27 & 1286.10 & 18005.41 & 55579.37 \\
\hline 41 & & 2169.75 & 30376.47 & \\
\hline 40 & & 514.11 & 7197.50 & \\
\hline 39 & 26 & 310.54 & 4347.62 & 9695.63 \\
\hline 38 & & 296.04 & 4144.55 & \\
\hline 37 & & 85.96 & 1203.46 & \\
\hline 36 & 25 & 1137.66 & 15927.30 & 15927.30 \\
\hline 35 & 24 & 439.35 & 6150.87 & 6150.87 \\
\hline 34 & 23 & 922.24 & 12911.40 & 12911.40 \\
\hline 33 & 22 & 69.17 & 968.36 & 968.36 \\
\hline 32 & 21 & 820.45 & 11486.37 & 11486.37 \\
\hline 31 & 20 & 274.06 & 3836.80 & 3836.80 \\
\hline 30 & 19 & 1608.90 & 22524.65 & 35384.67 \\
\hline 29 & & 918.57 & 12860.02 & \\
\hline 28 & 18 & 296.58 & 4152.10 & 4152.10 \\
\hline 27 & 17 & 978.23 & 13695.20 & 13695.20 \\
\hline 26 & 16 & 555.84 & 7781.72 & 8497.25 \\
\hline 25 & & 51.11 & 715.53 & \\
\hline 24 & 15 & 158.68 & 2221.51 & 3614.30 \\
\hline 23 & & 99.49 & 1392.79 & \\
\hline 22 & 14 & 685.37 & 9595.16 & 9595.16 \\
\hline 21 & 13 & 378.12 & 5293.66 & 5293.66 \\
\hline 20 & 12 & 447.23 & 6261.18 & 10892.21 \\
\hline 19 & & 187.93 & 2631.05 & \\
\hline 18 & & 82.51 & 1155.10 & \\
\hline 17 & & 60.35 & 844.88 & \\
\hline 16 & 11 & 1039.16 & 14548.25 & 14548.25 \\
\hline 15 & 10 & 201.24 & 2817.42 & 2817.42 \\
\hline 14 & 9 & 363.44 & 5088.11 & 9961.03 \\
\hline 13 & & 130.24 & 1823.42 & \\
\hline 12 & & 51.22 & 717.15 & \\
\hline 11 & & 166.60 & 2332.36 & \\
\hline 10 & 8 & 101.44 & 1420.19 & 1420.19 \\
\hline 9 & 7 & 126.21 & 1766.95 & 1766.95 \\
\hline 8 & 6 & 481.85 & 6745.96 & 6745.96 \\
\hline 7 & 5 & 375.25 & 5253.47 & 5253.47 \\
\hline 6 & 4 & 193.37 & 2707.21 & 14822.44 \\
\hline 5 & & 865.37 & 12115.23 & \\
\hline 4 & 3 & 682.83 & 9559.66 & 15247.78 \\
\hline 3 & & 406.29 & 5688.11 & \\
\hline 2 & 2 & 177.60 & 2486.45 & 2486.45 \\
\hline 1 & 1 & 556.96 & 7797.45 & 7797.45 \\
\hline
\end{tabular}


沟，基本上每年都有产沙洪水的发生，我们认为，这 54 次产沙洪水发生于 1569 年后的 31 年内, 或略多年 份内.

\section{3 次洪水产沙量和年产沙量}

根据淤积台地的顶、底面积和各洪水沉积旋迴的 厚度, 采用雉台法求算了沉积旋迴的淤积泥沙体积 和重量(容重 $r=1.4 \mathrm{t} \cdot \mathrm{m}^{-3}$ ), 计算了次暴雨产沙模数和 年产沙模数 (表 1). 垂直长度 $12.73 \mathrm{~m}$ 的坝库淤积泥沙 总体积 $27965.29 \mathrm{~m}^{3}$ ，旋迴的淤沙体积介于 51.11 $2169.75 \mathrm{~m}^{3}$. 次暴雨洪水的产沙模数介于 $715.53 \sim$ $30376.47 \mathrm{t} \cdot \mathrm{km}^{-2}$, 平均 $7105.87 \mathrm{t} \cdot \mathrm{km}^{-2}$; 年产沙模数 介于 $968.36 \sim 55579.37 \mathrm{t} \cdot\left(\mathrm{km}^{2} \cdot \mathrm{a}\right)^{-1}$, 平均 12629.49 $\mathrm{t} \cdot\left(\mathrm{km}^{2} \cdot \mathrm{a}\right)^{-1}$. 和淮宁河 1985 年的年均输沙模数相比, 黄土洼一带 450 年前的土壤侵蚀强度和现代差别不 大, 这可能和明代陕北长城一带戍边屯星, 大规模开 荒有关. 第 27 年后, 年产沙模数急遽增加, 第 27 31 年 5 年的平均产沙模数高达 $31309.12 \mathrm{t} \cdot\left(\mathrm{km}^{2} \cdot \mathrm{a}\right)^{-1}$, 这 5 年的产沙量远较前 27 年为高的原因, 可能是滑 坡灾害发生后，群众逃离，农田撂荒，植被迅速恢复， 流域产沙量处于低水平; 20 多年后，群众对滑坡灾害 的印象逐渐淡薄, 又回来复圼撂荒农田, 导致土壤侵 蚀加剧, 产沙量急剧增加.

\section{4 结语}

( i ) 黄土丘陵区淤地坝库内沉积泥沙完整的保 存了流域内侵蚀产沙及植被覆盖等方面的信息，通 过对淤积泥沙体积和狍粉含量、种属的分析, 可以较
好的恢复流域及区域内的侵蚀产沙状况及土地利用 和植被覆盖变化的历史. 黄土丘陵区小流域众多的 历史时期聚湫坝和现代淤地坝, 为相应课题的研究 提供了丰富的素材, 黄土聚湫坝库沉积泥沙研究大 有可为.

(ii ) 由于粗、细泥沙在水中自由沉降速度的差 异, 沉积旋迴顶部泥沙粒度细, 底部粗. 而孢粉在沉 降过程中, 由于比重远小于泥沙比重, 大部分富集于 沉积旋迴顶部. 通过比较整个沉积剖面的泥沙粒度和 狍粉浓度的变化, 并与野外取样情况相印证, $12.73 \mathrm{~m}$ 的沉积剖面可分为 54 个次洪水沉积旋迴, 旋迴最厚 $84 \mathrm{~cm}$, 最薄仅 $2.6 \mathrm{~cm}$. 每年末次洪水沉积旋迴暴露 于空气中, 旋迴顶部经历冬季冻结融解过程扰动, 形 成“冻豆腐”状的融冻扰动层结构. 54 次洪水沉积旋迴 中有 31 个融冻扰动层, 表明 54 次洪水为 31 年内发 生, 平均每年 1.7 次.

(iii) 根据沉积旋迴厚度和淤积台地顶部面积, 采用雉台法估算, 次洪水产沙模数介于 715.53 $30376.47 \mathrm{t} \cdot \mathrm{km}^{-2}$, 平均 $7105.87 \mathrm{t} \cdot \mathrm{km}^{-2}$; 年产沙模数 介于 $968.36 \sim 55579.37 \mathrm{t} \cdot\left(\mathrm{km}^{2} \cdot \mathrm{a}\right)^{-1}$, 平均 12629.49 $\mathrm{t} \cdot\left(\mathrm{km}^{2} \cdot \mathrm{a}\right)^{-1}$. 与淮宁河中游年输沙模数比较, 明代该 区域的年产沙模数与现代年产沙模数接近. 第 $27 \sim 31$ 年间, 年产沙模数明显增大, 5 年内的年均产沙模数 达 $31309.12 \mathrm{t} \cdot\left(\mathrm{km}^{2} \cdot \mathrm{a}\right)^{-1}$. 后 5 年产沙模数急剧增加, 结合明代当地戍边屯星的历史分析，推测滑坡发生 后, 当地土地被短暂撂荒, 自然植被得以恢复, 后又 重新被大规模开发.

致谢样品的测试得到中国地质科学院水文地质环境地质研究所童国榜研究员的帮助, 谨此致谢.

\section{参考文献}

1 张信宝, 温仲明, 冯明义. 应用 ${ }^{137} \mathrm{Cs}$ 示踪技术破译黄土丘陵区小流域坝库沉积赋存的产沙记录. 中国科学 D 辑: 地球科学, 2007, 50(2): 254-260

2 庞尚鹏. 《清理延绥电田疏》《明经世文编》。卷三五九

3 钱林清. 黄土高原气候. 北京: 气象出版社, 1991. 335-336

4 叶青超, 等. 黄河流域环境演变与水沙运行规律研究. 济南: 山东科学技术出版社, 1994. 33

5 王开发, 王宪曾. 孢粉学概论. 北京: 北京大学出版社, 1983. 52 